\title{
STRUCTURE AND FUNCTION OF SUBCELLULAR COMPONENTS
}

$\mathrm{T}$

HE Biochemical Society held a symposium on "Structure and Function of Subcellular Com. ponents" in the Senate House of the University of London on February 23. The symposium was attended by more than two hundred members of the Society and their guests.

Sir Rudolph Peters, chairman for the morning session, introduced the subject of the symposium.

Dr. J. D. Robertson gave an illustrated survey of the electron microscopical view of the ultrastructure of certain cells, describing particularly the membranes of the endoplasmic reticulum, of the mitochondria, and of the cells and subcellu'lar components of nervous tissue. He believed that the endoplasmic reticulum formed a continuous aqueous channel between the internal medium of the nucleus and the extracellular medium. This supposed channel was suggested as the path of transfer of substances between the cell and its milieu. Dr. Robertson supported Palade's conception of mitochondrial structure, regarding the inner membrane as the much infolded boundary between an internal and an extermal mitochondrial chamber. He agreed with the findings of Freeman, that both mitochondrial membranes are double. He showed the close approximation of the membranes of intraneuronal and neuromuscular junctions, and the apparent connexion between vesicular bodies and (tubular ?) axon filaments less than $100 \mathrm{~A}$. thick. The relationship between the cell membranes of a Schwann cell wrapped around the axon was compared with the spiral appearance of transverse sections through the myelin sheath. To conclude, Dr. Robertson demonstrated the resolution of the $100 \mathrm{~A}$. period of myelin sheath into a $50 \mathrm{~A}$. period, especially in sections fixed in potassium permanganate. He speculated on how the laminæ $50 \mathrm{~A}$. thick might be made up of monolayers of lipid and protein.

Dr. S. J. Holt described the principles and potentialities of cytochemical staining methods for the study of intracellular enzyme distribution. He outlined the criteria to which staining methods should conform in order that the staining pattern produced might indicate the quantitative as well as the qualitative distribution of the activity of a given enzyme. The performance of a staining procedure for esterases, based upon the use of substituted indoxyl acetates as substrates, and depending upon the liberation of indoxyl by the enzyme and subsequent oxidation to an indigoid dye, was compared with the behaviour deduced from a theoretical treatment of the staining process. The predictions of the theory concerning the factors required to increase the resolution of the cytochemical staining have been verified experimentally, and it was shown that, under appropriate conditions, the esterase activity can probably be located with a precision of about $0 \cdot 5 \mu$. The possibilities of the method were nicely illustrated by the staining of the acetylcholine esterase near the muscle and/or nerve cell membranes of the muscle end-plate. Dr. Holt suggested that cytochemical staining might be adapted to measure the Michaelis constant of an enzyme in situ for purposes of identification.

The chairman for the afternoon session was Prof. D. D. Woods. He introduced Prof. L. Ernster, who dealt with three examples of the effect of spatial arrangement on the activities of enzyme systems concerned in energy transformation. Prof. Ernster described the close connexion between the changes in coupling of phosphorylation to oxidation, the appearance of the latent adenosine triphosphatase, and the changes in morphology (and 'loosening' of structure) of mitochondria subjected to various chemical and physical treatments. He sought to explain the exceptional behaviour of the oxidatively phosphorylating particles isolated from digitonintreated mitochondria by a tightness of binding of the essential components of the system, which he sup. posed to be artificially imposed by the digitonin treatment. The system responsible for oxidative phosphorylation was believed to be part of the mito. chondrial membrane. Prof. Ernster went on to describe the difference in the pathway and general characteristics of the oxidation of intra- and extramitochondrial reduced diphosphopyridine nucleotide. For his last example, Prof. Ernster outlined the work in which he and his collaborators had shown the normal pathway of isocitrate oxidation to be through the diphosphopyridine nucleotide-linked intramitochondrial enzyme and not, as was formerly supposed, through the much more active triphosphopyridine nucleotide-linked extramitochondrial isocitric dehydrogenase. Prof. Ernster suggested that the triphosphopyridine nucleotide of the cytoplasm, which exists mainly in the reduced form, channels hydrogen to essential reductive steps of metabolism; and that, dependent upon the extent of 'loosening' of mitochondrial structure, the double-specific pyridine nucleotide-linked enzymes might regulate the channelling of hydrogen between the two pyridine nucleotides.

Dr. P. Mitchell outlined the progress of work on the relationship between the structure of the membranes of bacteria and the movements of solutes between the cytoplasm and the external medium. It was shown that the transport of inorganic phosphate across bacterial membranes has features in common with mitochondrial oxidative phosphorylation; and that the lipoprotein plasma-membrane of bacteria contains most of the cytochrome of the cell and the bulk of a number of oxidative and hydrolytic enzymes. Dr. Mitchell described recent work in which he and his collaborators have shown the strict coupling of the permeation of amino-acids, carbohydrates and their derivatives to metabolism. These observations have led to the formulation of a general theory of membrane transport-an extension of the previous hypothesis that enzymes conduct metabolites through the bacterial membrane. According to this theory, membrane-transport reactions are, in general, both formally and physically equivalent to group-transfer reactions catalysed by enzymes. It was suggested that this theory would explain the apparent contradiction between the low physical permeability of bacterial membranes and the easy accessibility of the metabolic systems to the nutrients of the medium; and that it would also explain the biochemical mechanism of outward transfer and polymerization of the components of the external cell-wall.

Dr. K. Rees, giving the last paper of the sym. posium in collaboration with Dr. J. D. Judah, 
described the changes in the cellular components of rat livers damaged by administration of carbon tetrachloride, or of carcinogens, particularly thioacetamide. The reduced oxidative activity of livers of animals treated with carbon tetrachloride was ascribed to mitochondrial damage. It was shown that the loss of pyridine nucleotides, which accompanies ageing of normal isolated mitochondria, was increased at an early stage in animals to which carbon tetrachloride had been administered; and it was suggested that the early mitochondrial injury visible in otherwise normal livers of rats poisoned by carbon tetrachloride could be attributed to a localization of the carbon tetrachloride leading to changes of mitochondrial 'permeability'. In animals with chronic thioacetamide poisoning at the pre-cancerous stage, the ageing of the mitochondria could be reversed by pyridine nucleotides or by versene, although there appeared to be no change in 'permeability' to the nucleotides and no uncoupling of oxidative phosphorylation. There was, however, a reduction in phosphatidic acid synthesis. The nuclei and nucleoli of these livers were enlarged and showed an increased ratio of ribonucleic acid to protein; and incorporation of glycine was more rapid than in the controls. Acute thioacetamide poisoning caused a reduced rate of oxidation of fatty and keto acids by the mitochondria. This effect could be reversed by versene, and was thought to be due to ionic imbalance in the tissue, leading to accumulation of calcium ions.

During the discussion, Dr. Judah described some work on mitochondrial fractionation in which it had been possible to destroy the adenosine triphosphateinorganic phosphate exchange reaction without uncoupling oxidation from phosphorylation. This was contested by Prof. Ernster, on the ground that the presence of substrate during oxidation might have reactivated the system catalysing exchange. Further lively discussion did not resolve this important point. Otherwise, the discussion of the papers was concerned with issues of interpretation and with points of detail.

The formal papers and the discussion of the symposium are to be published as a book.

Peter Mitchell

\section{LINEN INDUSTRY RESEARCH ASSOCIATION \\ REPORT FOR 1956}

$\mathrm{T}$ HE report of the Council of the Linen Industry Research Association for 1956* records continued co-operation with the Irish Linen Guild but a slight fall in membership, from 276 to 269 . Dr. A. J. Turner retired at the end of March after sixteen years as director and was succeeded by Mr. D. A. DerrettSmith.

Basic research was carried out during 1956 on the behaviour of fibres during drafting and carding, and on the blending of flax with 'Terylene', nylon and 'Fibro'. Investigations have been made to determine the finest count of yarn which can be wet-spun using various proportions of flax and man-made fibres. Work continued on the new servo-drafting control system for reducing yarn irregularities and a study

* Linen Industry Research Association. Report of the Council, * Linen Industry Research Association. Report of the Council,
1956. $\mathrm{Pp} .20$. (Lambeg: Linen Industry Research Association, 1957.) of nap formation in flax slivers indicated that nap in yarns can be reduced appreciably by changes in processing methods. Special warping creels have been developed for linen yarns and a survey has been made of the cones and cheeses now in use. Two new forms of shuttle guard have been developed to decrease the risk of injury from flying shuttles. Work on lubricating materials has provided an explanation of difficulties experienced with certain oils and much progress has been made in sizing spun yarns from man-made fibres. The penetration problems which arise in dyeing and finishing linen have been examined in the light of experience gained with linen fabries that have been rendered nonswelling, and increased efficiency in applying flameproofing emulsions has been thus obtained. Methods for applying thermo-setting resins to linen fabrics to confer crease-resistance have been modified and an instrument has been developed for testing the waterproofness of wax- and chemical dry-proofed canvases.

At the thirty-seventh annual general meeting of the Association on January 4, the chairman, Mr. H. B. McCance, expressed concern about the possible adverse effect of the Restrictive Trade Practices Act on co-operative research. Mr. D. A. Derrett-Smith, referring to flax production, said that the Dutch whiteblossom Wiera variety is promising to meet growing conditions in Northerm Ireland without detriment to yield or quality. Because it is becoming difficult to find labour for dam-retting or tank-retting, work is proceeding on the direct comparison of the green flax process with Irish dam-retted flax for wet-spinning. Besides such fundamental research, last year 662 research problems proposed by members were dealt with at Lanbeg, as well as 2,520 routine tests, and it had been necessary to ask members to limit requests for such tests so far as possible. Mr. Derrett-Smith said that several promising young graduates had been recruited to the staff, and under the re-introduced scholarship scheme seven students were receiving practical training during the day and attending courses of evening study at the Belfast College of Technology leading to the B.Sc. degree in chemical technology.

\section{THE COPRA INDUSTRY OF ZANZIBAR}

COPRA is the dried 'meat' of the coconut and A contains about 67 per cent of an excellent edible oil which is also used for making soap. Copra cake or meal is extensively used for animal feed or as fertilizer. The total annual world production of copra is about $1,780,000$ metric tons (1951), and of this about 3,500 tons and 12,000 tons are produced annually by the islands of Pemba and Zanzibar, respectively. The problems associated with production have been described by D. W. Hall (Col. Plant and Anim. Prod., 5, No. 4).

The islands of Zanzibar and Pemba are heavily wooded with coconut trees, and each tree produces. 20-60 fruits a year. The average annual yield on Government plantations is $\mathbf{4 0}$ fruits per year.

Labour gangs climb the trees and cut down the fruits, and other gangs collect the fallen fruits into piles. The fruits are then transported to the main collecting centres, at each of which there is a kiln, or to individual kilns. The coconuts are left in heaps on 